\title{
SIMULTANEOUS ESTIMATION OF THIOCOLCHICOSIDE AND ACECLOFENAC BY HPTLC
}

\author{
PRATIMA SYAL* , RAVINDER KUMAR, GOVIND ARORA
}

Chitkara College of Pharmacy, Chandigarh-Patiala National Highway, Rajpura 140401, Patiala, Punjab, India

Email: pratimakumari2506@gmail.com

Received: 27 Jan 2017, Revised and Accepted: 20 Apr 2017

\begin{abstract}
Objective: Therefore the aim of the present work was to develop simple, precise and accurate HPTLC method for simultaneous determination of THIO and ACE in pharmaceutical dosage form and application of the method for dissolution study with help of HPTLC method.

Methods: The TLC procedure was optimized in view to develop a simultaneous assay method for THIO and ACE. HPTLC Pre-coated plates silica gel $60 \mathrm{~F}_{254} 20 \times 10 \mathrm{~cm}$, layer thickness $0.2 \mathrm{~mm}$ (Merck, Germany). The samples were spotted in the form of bands (8 mm) with a Camag 100 microliter sample (Hamilton) syringe on silica gel precoated aluminium $60 \mathrm{~F}_{254}$ plates. The mobile phase consisted of methanol: chloroform: water (9.6: $0.2: 0.2 \mathrm{v} / \mathrm{v} / \mathrm{v}$ ) and $10 \mathrm{ml}$ of mobile phase were used per chromatography run. Plates were scanned over the range of 200-400 $\mathrm{nm}$ and the spectra were overlain.

Results: The detector response was found to be linear in the concentration range of 0.03-0.180 $\mu \mathrm{g} / \mathrm{band}$ and $0.75-4.5 \mu \mathrm{g} / \mathrm{band}$ for THIO and ACE and noting the peak areas. Accuracy of the assay method was evaluated with the recovery of the standards from excipients. The mean percentage recoveries obtained for THIO and ACE were $99.34 \%$ and $99.08 \%$, respectively, reported. The peak purity of both drugs was assessed by comparing
\end{abstract} the respective spectra of standard drugs and samples at peak start, peak apex and peak end positions of the spot.

Conclusion: HPTLC, with its advantage of low operating cost, high sample thought and minimum sample preparation need is now days preferred as routine analytical techniques for control and assurance. The validated HPTLC method employed here proved to be simple, fast, accurate, precise and sensitive, thus can be used for routine analysis of Thiocolchicoside and Aceclofenac in tablet dosage form.

Keywords: HPTLC, Thiocolchioside, THIO and ACE, ICH guidelines, Standard stock solutions

(c) 2017 The Authors. Published by Innovare Academic Sciences Pvt Ltd. This is an open access article under the CC BY license (http://creativecommons.org/licenses/by/4.0/) DOI: http://dx.doi.org/10.22159/ijcpr.2017v9i4.20957

\section{INTRODUCTION}

HPTLC [10-16]

HPTLC is the most simple separation technique today available to the analyst.

It can simultaneously handle several samples even of different nature and composition supporting several analysis at a given time.

High-performance thin layer chromatography, also known under the synonym planer chromatography, is a modern, powerful analytical technique with separation power, performance and reproducibility superior to classic TLC. It involves the same theoretical principle of thin layer chromatography wherein substances are separated on the basis of their differential migration in the system of two phases on a special type of plates. This technique is mostly used in many fields both for qualitative and quantitative (identification and estimation) of constituents mixture. This can easily be validated and fully compliant with GMP.
Advantages of HPTLC
1) Short development time.
2) Wide choice of stationary phase.
3) Early recovery of separated components.
4) Superior separation effects.
5) Easy visualization of separated compounds.

The main and important steps involved in this are as follows:

\section{Sample preparation}

F normal phase chromatography using silica gel/Alumina percolated plates, solvent generally should be non-polar and volatile type. Since polar solvent tend to give circular shape at the origin. For reverse phase chromatography usually, polar solvents are used for dissolving the sample.

\section{Selection of chromatographic layer}

Selection of layer depends on the nature of the material to be separated.

Commonly used materials are Silica gel 60F, Allumina, Cellulose, PEI, impregnated cellulose etc.

\section{Plates}

Standard size plates for HPTLC are manufactured by various companies which are most satisfactory. Handmade plates can be prepared and used which are economical. Generally, plates of $20 \mathrm{X}$ $20 \mathrm{~cm}$ or $5 \times 7.5 \mathrm{~cm}$ size having $100-250 \mathrm{~mm}$ adsorbent thickness are used for quantitative analysis. Silica gel 60F254 having a pore size $6 \mathrm{~mm}$ with a fluorescent indicator is a coat material. The basic difference in TLC and HPTLC plate is particle size of coated material which is 5-20 $\mu \mathrm{m}$ for TLC and 4-8 $\mu \mathrm{m}$ for HPTLC.

\section{Pre-washing}

Plates need to be pre-washed to remove water vapors or other volatile impurities, which might get trapped in the plates. These gives dirty zones and spots on the plates. To avoid this, plates are cleaned by using methanol as a solvent by ascending or descending or by dipping continuous mode.

\section{Conditioning}

The pre-washed plates exposed to humidity and surroundings are needed to be activated by placing them in the oven at $120^{\circ} \mathrm{C}$ for 15 to $20 \mathrm{~min}$. This process is known as conditioning. This allows the active centers of coating materials attenuated for better separation of sample material. 


\section{Sample application}

It is a most important step for obtaining good resolution and results. Application of 1.0-5 $\mu \mathrm{l}$ is most satisfactory, for HPTLC, application of the sample and standard as a band gives better separation, equal Rf values and less spot broadening. This sample application is carried out by Linomat type applicator on the plates which give a uniform, safe and standard results.

\section{Preconditioning (Chamber saturation)}

This has a profound influence on the effective separation of the sample. For low polarity mobile phase there is no need of saturation, however, saturation is desirable in the case of highly polar mobile phases. Partial saturation is recommended for mobile phase composition leading to phase separation. For reverse phase chromatography, it is essential to saturate the chamber with methanol or polar solvent.

\section{Mobile phase}

The selection of appropriate mobile phase is based on the trial and error in which chemical properties of solute and solvent, the solubility of analyte absorbent layer etc. are considered along with analyst own experience.

\section{Chromatographic development}

Various forms of chromatographic development like ascending, descending, and horizontal, continuous, gradient can be tried. For HPTLC plates, migration distance of $5-6 \mathrm{~mm}$ is sufficient. After development, plates are removed from the chamber and dried to remove traces of mobile phase. Common problems encountered during chromatographic development are as follows:

\section{(a) Tailing}

This may occur due to the presence of traces of impurities or due to the presence of more than one ionic species of substances being chromatographed. This can be reduced by buffering the mobile phase system with acidic (1-2\% acetic acid) or basic (ammonia) solution. It keeps the materials to be separated in non-ionic forms.

\section{b) Diffusion}

This is seen as zones of chromatographic plates. This may arise due to non-uniformity of mobile phase, longitudinal diffusion between the mobile phase and stationary phase or due to non-equilibrium of stationary phase.

\section{Detection spots}

Immediately after the development step is completed. The plates are removed from the chamber and dried to remove traces of mobile phase. Generally, detection can be done by iodine vapour in iodine chamber. Alternatively, detection can be done by visual inspection examination at $254 \mathrm{~nm}$ of the ultraviolet region in UV cabinet.

\section{Scanning and documentation}

Now day HPTLC equipment are supplied with computer and data recording and staring devices. The development of HPTLC plates are scanned at selected UV region wavelength by the instrument and the detected spots are seen on the computer in the form of peaks. The scanner converts band into peaks and peak height or area is related to the concentration of the substance on the spot.

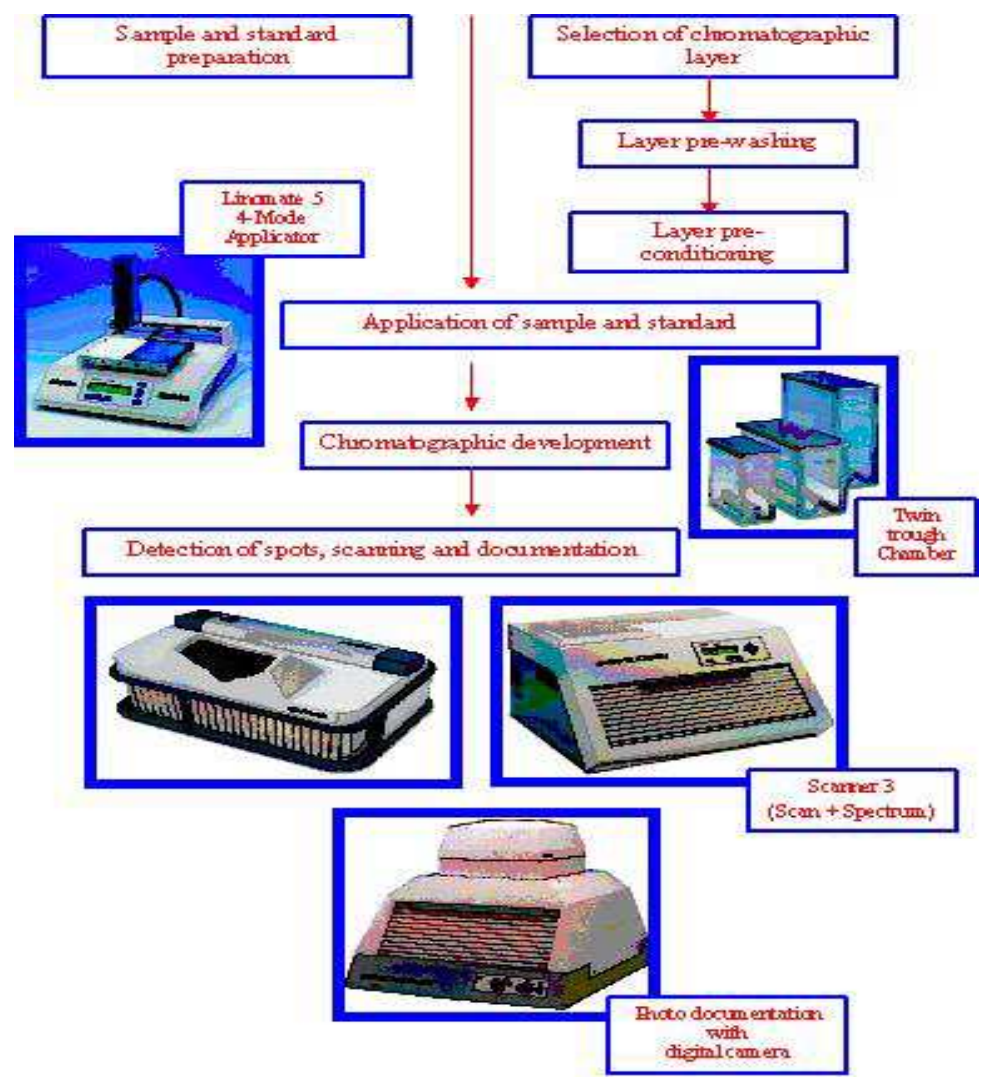

\section{MATERIALS AND METHODS}

\section{Materials and reagents}

Tablets used for analysis were ZIX-MR manufactured by Jenburk Pharmaceuticals ltd. Andheri, Mumbai were used for analysis containing THIO $4 \mathrm{mg}$ and ACE $100 \mathrm{mg}$ per tablet. Pure drug sample of THIO, \% purity 98.5 and ACE, \% purity 99.8 was kindly supplied as a gift sample by Medley Pharmaceuticals Ltd. Baddi, and Curex Pharmaceuticals Jalgaon, India, respectively. These samples were used without further purification. HPTLC precoated plates silica gel $60 \mathrm{~F}_{254} 20 \times 10 \mathrm{~cm}$, layer thickness $0.2 \mathrm{~mm}$ (Merck, Germany). Analytical grade methanol, chloroform was procured by Merck Chemicals (Mumbai, India). 


\section{Chromatographic parameters}

The mobile phase consisted of methanol: chloroform: water 9.6:0.2:0.2(v/v/v). After developments, the plate was immediately dried with the help of dryer and was observed under CAMAG TLC Visualizer. The well-resolved bands of drugs were scanned at 254 nm with CAMAG TLC scanner III densitometers controlled by WINCAT's software version 4 .

\section{Instrumentation}

The samples were spotted in the form of bands $(8 \mathrm{~mm})$ with a Camag 100 microlitre sample (Hamilton) syringe on silica gel precoated aluminium $60 \mathrm{~F}_{254}$ plates, $(10 \mathrm{~cm} \times 10 \mathrm{~cm}$ with $250 \mathrm{~mm}$ thickness; E. Merck) using a Camag Linomat V sample applicator. A constant application rate of $150 \mathrm{~nL} \mathrm{~s}^{-1}$ was used and the space between two bands was $12 \mathrm{~mm}$. The slit dimension was kept at 6 $\mathrm{mm} \times 0.30 \mathrm{~mm}$ and the scanning speed was $20 \mathrm{~mm} \mathrm{~s}^{-1}$.

The mobile phase consisted of methanol: chloroform: water (9.6: $0.2: 0.2 \mathrm{v} / \mathrm{v} / \mathrm{v}$ ) and $10 \mathrm{ml}$ of mobile phase were used per chromatography run. Linear ascending development was carried out in a $10 \mathrm{~cm} \times 10 \mathrm{~cm}$ twin trough glass chamber (Camag) saturated with the mobile phase and pad which is previously soaked in the mobile phase. The optimized chamber saturation time for the mobile phase was $45 \mathrm{~min}$ at room temperature $\left(25^{\circ} \mathrm{C} \pm 2\right)$ at a relative humidity of $60 \% \pm 5$. The length of each chromatogram run was $8 \mathrm{~cm}$. Following the development, the TLC plate was dried with the help of hot air drier. The plate was scanned over $85 \mathrm{~mm}$ distance. Densitometric scanning was performed using a Camag TLC scanner III in the absorbance mode at $254 \mathrm{~nm}$ and operated by win CATS software (V 1.4.4, Camag). The source of radiation used was a deuterium lamp emitting a continuous UV spectrum between 190 and $400 \mathrm{~nm}$.

The retention factors of THIO and ACE were recorded in Densitogram of THIO and ACE are shown in fig. 1.1.

THIO: $0.70 \pm 0.05$

ACE: $0.83 \pm 0.05$

\section{Preparation of standard stock solutions}

$50 \mathrm{mg}$ of each drug THIO and ACE were weighed separately and dissolved in $20 \mathrm{ml}$ of HPLC grade methanol and then the volume was made up to $50 \mathrm{ml}$ so as to get the concentration $1 \mathrm{mg} / \mathrm{ml}$. From each of these solutions, $1 \mathrm{ml}$ of solution was pipette out and transferred to $10 \mathrm{ml}$ volumetric flasks and volume were made up to the mark using methanol so as to get the concentration $100 \mu \mathrm{g} / \mathrm{ml}$.

\section{Selection of analytical wavelength}

From the standard stock solution further dilutions were done using mobile phase and scanned over the range of $200-400 \mathrm{~nm}$ and the spectra were overlain. It was observed that both drugs showed considerable absorbance at $254 \mathrm{~nm}$ as shown in fig. 1.2

\section{Formulation analysis}

Twenty tablets were weighed accurately and a quantity of tablet powder equivalent to $4 \mathrm{mg}$ of THIO and $100 \mathrm{mg}$ of ACE was weighed and dissolved in the $40 \mathrm{ml}$ of methanol with the aid of ultrasonication for $10 \mathrm{~min}$ and the solution was filtered through Whatman paper No. 41 into a $50 \mathrm{ml}$ volumetric flask. The filter paper was washed with methanol, adding washings to the volumetric flask and volume was made up to the mark with methanol. From the filtrate, appropriate dilution was prepared in the mobile phase to get a solution of $4 \mu \mathrm{g} / \mathrm{ml}$ of THIO and $100 \mu \mathrm{g} / \mathrm{ml}$ of ACE. These solutions were spotted keeping an appropriate distance between spots. The results obtained are shown in table 2.1.

Brand: ZIX-MR

Contents: Thiocolchicoside- $4 \mathrm{mg}$

Aceclofenac- $100 \mathrm{mg}$

Manufacturer: JENBURK PHARMACEUTICALS Ltd.

\section{Method development}

\section{Method validation}

As per the ICH guidelines, the method validation parameters checked were linearity, accuracy, precision, limit of detection, limit of quantitation and robustness and specificity.

\section{Linearity}

Stock standard solution was prepared by dissolving $50 \mathrm{mg}$ of THIO and $50 \mathrm{mg}$ of ACE in $50 \mathrm{ml}$ methanol $(1000 \mu \mathrm{g} / \mathrm{ml})$. Suitable dilutions using mobile phase were made from the standard stock solution containing $4 \mu \mathrm{g} / \mathrm{ml}$ of THIO and $100 \mu \mathrm{g} / \mathrm{ml}$ of ACE. From this stock solution, THIO and ACE were spotted on the TLC plate to obtain final concentration 30-180 ng/band and 750-4500 ng/band for THIO and ACE, respectively. Each concentration was spotted 3 times on the TLC plate. The plate was developed on the mobile phase.

\section{Accuracy}

The accuracy of the assay method was evaluated with the recovery of the standards from excipients. Recovery studies were carried out by applying the method to drug content present in tablet dosage form to which known amount of mix standard of THIO and ACE was added at $50 \%, 100 \%$ and $150 \%$ levels. The technique involves the addition of standard drug solution to pre-analysed sample solution. From these solutions, appropriate volumes were applied as a band and the area was noted after the development of plate. At each of the levels, three determinations were performed and results were obtained.

\section{Precision}

The precision of the method was demonstrated by Intra-day and interday variation studies. In the intra-day studies, 3 repeated measurements of standard and sample solutions were made in a day and percentage RSD were calculated. In the inter-day variation studies, 3 repeated measurements of standard and sample solutions were made on 3 consecutive days and percentage RSD were calculated.

\section{Limit of detection and limit of quantification}

The Limit of Detection (LOD) is the smallest concentration of the analyte that gives the measurable response and Limit of Quantification (LOQ) is the smallest concentration of the analyte, which gives a response that can be accurately quantified. LOD and LOQ were calculated using the following formula:

LOD $=(3.3 \times \sigma) / b$
LOQ $=(10 \times \sigma) / b$

Where $\sigma=$ Standard deviation of the response

\section{$\mathrm{b}=$ Slope of the calibration curve}

\section{Robustness}

By introducing small changes in the mobile phase composition, the effects on the results were examined. Mobile phases having different composition like methanol: chloroform: water $(9.6: 0.2: 0.2 \mathrm{v} / \mathrm{v} / \mathrm{v})$, $(9.4: 0.4: 0.2 \mathrm{v} / \mathrm{v} / \mathrm{v}), \quad(9.5: 0.2: 0.3 \mathrm{v} / \mathrm{v} / \mathrm{v} / \mathrm{v})$ were tried and chromatograms were run. Time from spotting to chromatography and from chromatography to scanning was varied from $0,20,40$ and $60 \mathrm{~min}$. Robustness of the method was done at three different concentration levels $30,60,90 \mathrm{ng}$ per band and 750, 1500, $2250 \mathrm{ng}$ per band for THIO and ACE, respectively. Robustness of the method was determined by carrying out the analysis under conditions during which mobile phase ratio and ambient temperature were altered and the changes on the $\mathrm{R}_{\mathrm{f}}$ values were noted.

\section{Specificity}

The specificity of the method was ascertained by overlaying UV spectra of spots for standard drug and sample.

\section{Method optimization}

The TLC procedure was optimized in view to develop a simultaneous assay method for THIO and ACE. The mixed standard stock solution was spotted onto TLC plates and run in different solvent systems. 
Initially, solvents like toluene, chloroform and methanol were tried in different ratios. Based on the results of these initial trials, toluene, chloroform and methanol in the ratio (9.4: 0.4: 0.2) was selected where THIO and ACE were poorly resolved and RF values were also less. To increase the resolution between THIO and ACE, toluene was replaced with water, then methanol, chloroform and water in the ratio (9.6: 0.2: 0.2) were used. In this mobile phase, THIO and ACE were well resolved and RF values were good. Finally, the optimum mobile phase consisted of Methanol: chloroform: water in the ratio of (9.6: $0.2: 0.2 \mathrm{v} / \mathrm{v} / \mathrm{v}$ ) was chosen as the mobile phase for analysis. Other chromatographic conditions like chamber saturation time, run length, sample application rate and volume, sample application positions, the distance between tracks, detection wavelength, were optimized to give reproducible $\mathrm{R}_{\mathrm{f}}$ values, better resolution, and symmetrical peak shape for the two drugs. Densitometry scanning was performed at $254 \mathrm{~nm}$ for the detection of THIO and ACE with R value of 0.70 and 0.83 respectively. Well-defined spots of standards were obtained without chamber saturation.

\section{RESULTS AND DISCUSSION}

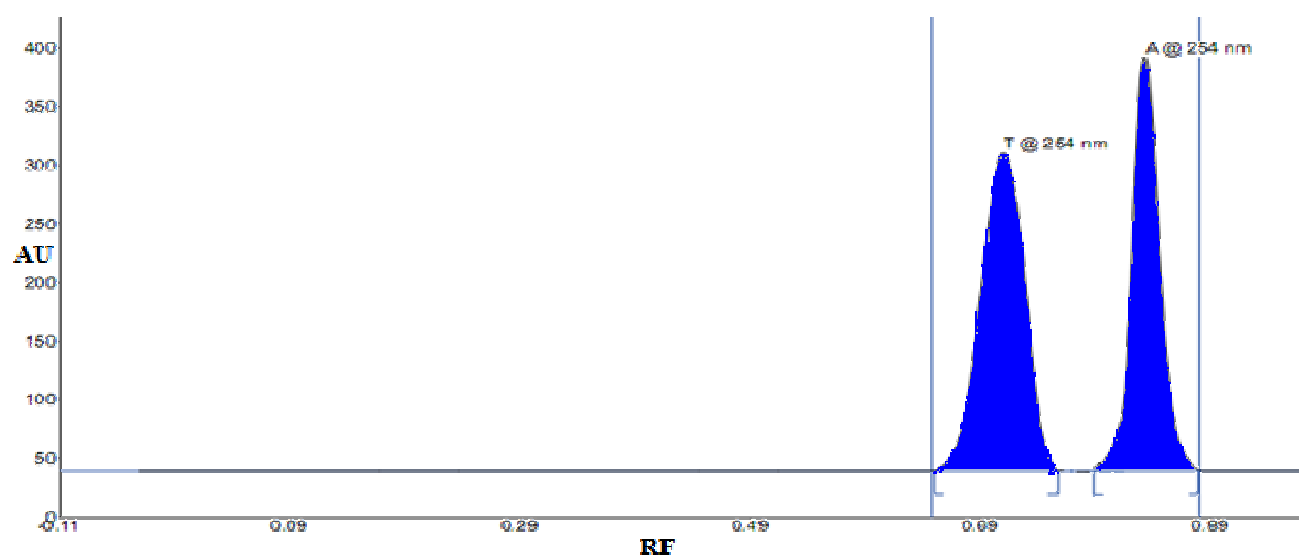

Fig. 1.1: Densitogram of THIO $(4 \mu \mathrm{g} / \mathrm{ml})$ and ACE $(100 \mu \mathrm{g} / \mathrm{ml})$

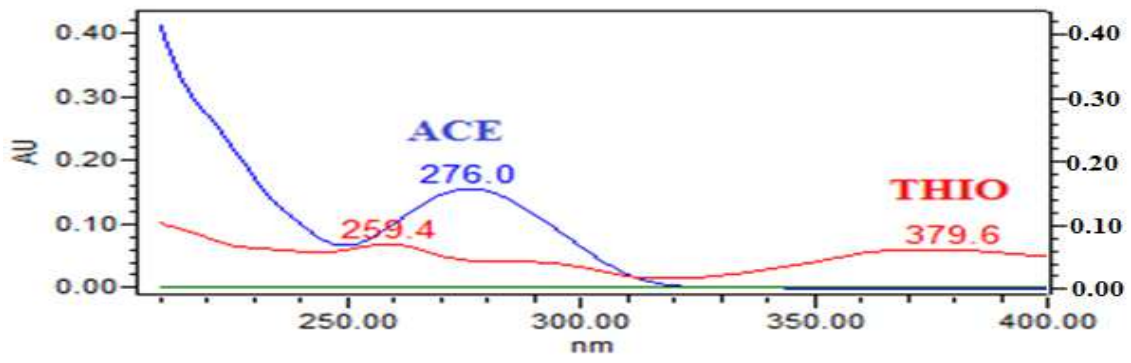

Fig. 1.2: Online overlain spectra of THIO $(4 \mu \mathrm{g} / \mathrm{ml})$ and ACE $(100 \mu \mathrm{g} / \mathrm{ml})$

Table 2.1: Analysis of tablet formulation

\begin{tabular}{|c|c|c|c|c|c|c|c|c|}
\hline \multirow[t]{2}{*}{ S. No. } & \multicolumn{2}{|c|}{ Label claim $(\mu \mathrm{g} / \mathrm{ml})$} & \multicolumn{2}{|c|}{ Amount found $(\mu \mathrm{g} / \mathrm{ml})$} & \multicolumn{2}{|c|}{$\%$ of label claim } & \multicolumn{2}{|c|}{ Peak purity } \\
\hline & THIO & ACE & THIO & ACE & THIO & ACE & $\mathbf{r}(\mathrm{S}, \mathrm{M})$ & r(M,E) \\
\hline 1. & 4 & 100 & 4.03 & 99.96 & 98.87 & 99.41 & 0.9991 & 0.9997 \\
\hline 2. & 4 & 100 & 3.97 & 98.89 & 99.55 & 99.47 & 0.9996 & 0.9999 \\
\hline 3. & 4 & 100 & 4.05 & 99.85 & 100.02 & 99.54 & 0.9992 & 0.9996 \\
\hline 4. & 4 & 100 & 3.99 & 100.01 & 99.92 & 100.01 & 0.9995 & 0.9994 \\
\hline 5. & 4 & 100 & 3.98 & 99.98 & 99.65 & 99.91 & 0.9994 & 0.9992 \\
\hline 6. & 4 & 100 & 4.01 & 98.87 & 99.78 & 99.45 & 0.9998 & 0.9993 \\
\hline Mean & & & 4.005 & 99.5933 & & & & \\
\hline SD & & & 0.028 & 0.506 & & & & \\
\hline$\%$ RSD & & & 0.702 & 0.508 & & & & \\
\hline
\end{tabular}

\section{Method validation}

\section{Linearity}

Linearity of the method was studied by spotting six concentrations of the drug prepared in the mobile phase in the range of $30-180 \mathrm{ng} / \mathrm{band}$ and $750-4500 \mathrm{ng} / \mathrm{band}$ for THIO and ACE. The results obtained are shown in table 3.1 and 3.2 the peak areas were plotted against the corresponding concentrations to obtain the calibration graphs.

\section{Precision}

The intra-day precision of the developed TLC method was determined by preparing the tablet samples of the same batch in nine determinations with three concentrations and three replicate each on the same day. The inter-day precision was also determined by assaying the tablets in triplicate per day for consecutive $3 \mathrm{~d}$. The result obtained for intraday and Inter-day variations are shown for THIO and ACE in table 3.3 and 3.4, respectively.

\section{Accuracy}

The accuracy of the assay method was evaluated with the recovery of the standards from excipients. The mean rercentage recoveries obtained for THIO and ACE were $99.34 \%$ and $99.08 \%$, respectively, reported in table 3.6 and 3.7. 
Table 3.1: Linearity of THIO (n=6)

\begin{tabular}{|c|c|c|c|c|c|c|}
\hline Standard? concentrations & $60 \mathrm{ng}$ & $90 \mathrm{ng}$ & $120 \mathrm{ng}$ & $150 \mathrm{ng}$ & $180 \mathrm{ng}$ & \\
\hline Replicates ? & Peak area & & & & & \\
\hline 1 & 1584 & 3176 & 4524 & 5930 & 7429 & 9080 \\
\hline 2 & 1582 & 3178 & 4628 & 5929 & 7418 & 9087 \\
\hline 3 & 1579 & 3198 & 4528 & 6016 & 7437 & 9198 \\
\hline 4 & 1568 & 3245 & 4537 & 5998 & 7558 & 9295 \\
\hline 5 & 1588 & 3179 & 4578 & 5986 & 7587 & 9195 \\
\hline 6 & 1559 & 3180 & 4525 & 5928 & 7477 & 9058 \\
\hline Mean & 1576.66 & 3192.66 & 4553.33 & 5964.5 & 7484.33 & 9152.16 \\
\hline SD & 10.02774 & 24.51983 & 38.19977 & 36.55931 & 65.47688 & 84.31966 \\
\hline$\%$ RSD & 0.636009 & 0.768005 & 0.838941 & 0.612948 & 0.874853 & 0.921308 \\
\hline
\end{tabular}

Table 3.2: Linearity of ACE $(n=6)$

\begin{tabular}{|c|c|c|c|c|c|c|}
\hline Standard? concentrations & $750 \mathrm{ng}$ & $1500 \mathrm{ng}$ & $2250 \mathrm{ng}$ & $3000 \mathrm{ng}$ & $3750 \mathrm{ng}$ & $4500 \mathrm{ng}$ \\
\hline Replicates ? & Peak are & & & & & \\
\hline 1 & 4150 & 8428 & 12750 & 16264 & 20750 & 25400 \\
\hline 2 & 4251 & 8429 & 12876 & 16397 & 20855 & 26549 \\
\hline 3 & 4149 & 8526 & 12987 & 16487 & 20987 & 25421 \\
\hline 4 & 4148 & 8578 & 12869 & 16589 & 21758 & 25406 \\
\hline 5 & 4157 & 8527 & 12967 & 16499 & 20765 & 25408 \\
\hline 6 & 4147 & 8446 & 12867 & 16264 & 20745 & 25466 \\
\hline Mean & 4167 & 8489 & 12886 & 16416.67 & 20976.67 & 25608.33 \\
\hline SD & 37.705 & 57.5963 & 77.46827 & 121.3983 & 359.4536 & 421.2445 \\
\hline$\%$ RSD & 0.904847 & 0.678482 & 0.601182 & 0.739482 & 1.713588 & 1.644951 \\
\hline
\end{tabular}

Regression equation: $\mathrm{Y}=5589 \mathrm{x}+49.33, \mathrm{r}=0.9993$

Table 3.3: Intraday and Inter-day precision of THIO (n=3)

\begin{tabular}{lll}
\hline THIO & Measured concentration (ng/spot), \% RSD & \\
\hline Conc. (ng/spot) & Intra day & Inter day \\
\hline 30 & $30.07,0.52$ & $30.81,0.87$ \\
60 & $60.91,0.63$ & $60.04,0.56$ \\
90 & $89.91,1.25$ & $29.14,0.74$ \\
\hline
\end{tabular}

Table 3.4: Intraday and Inter day precision of ACE $(n=3)$

\begin{tabular}{lll}
\hline ACE & Measured concentration (ng/spot), \% RSD & Inter day \\
\hline Conc. (ng/spot) & Intra day & $749.05,0.26$ \\
\hline $\mathbf{7 5 0}$ & $750.88,0.79$ & $1498.13,1.41$ \\
$\mathbf{1 5 0 0}$ & $1499.86,1.20$ & $2248.01,0.36$ \\
$\mathbf{2 2 5 0}$ & $2245.14,1.19$ & 26 \\
\hline
\end{tabular}

Table 3.5: Recovery studies of THIO

\begin{tabular}{|c|c|c|c|}
\hline \multirow[t]{4}{*}{ Thiocolchicoside } & \multicolumn{3}{|c|}{ Densitometric peak area } \\
\hline & \multicolumn{3}{|c|}{ Level of recovery } \\
\hline & $50 \%$ & $100 \%$ & $150 \%$ \\
\hline & 30ng/spot & $60 \mathrm{ng} / \mathrm{spot}$ & $90 \mathrm{ng} / \mathrm{spot}$ \\
\hline Replicate 1 & 1584 & 3176 & 4524 \\
\hline Replicate 2 & 1599 & 3245 & 4587 \\
\hline Replicate 3 & 1613 & 3189 & 4528 \\
\hline Mean & 1598.667 & 3203.333 & 4546.333 \\
\hline SD & 11.84155 & 29.93697 & 28.80201 \\
\hline$\%$ RSD & 0.740714 & 0.934557 & 0.633552 \\
\hline Mean conc. found (ng/ml) & 29.12 & 61.08 & 90.01 \\
\hline Mean \% Recovery & 99.58 & 99.98 & 99.45 \\
\hline
\end{tabular}

Table 3.6: Recovery studies of ACE

\begin{tabular}{|c|c|c|c|}
\hline \multirow[t]{4}{*}{ Aceclofenac } & \multicolumn{3}{|c|}{ Densitometric peak area } \\
\hline & \multicolumn{3}{|c|}{ Level of recovery } \\
\hline & $50 \%$ & $100 \%$ & $150 \%$ \\
\hline & $750 \mathrm{ng} / \mathrm{spot}$ & $1500 \mathrm{ng} / \mathrm{spot}$ & $2250 \mathrm{ng} / \mathrm{spot}$ \\
\hline Replicate 1 & 4150 & 8428 & 12750 \\
\hline Replicate 2 & 4196 & 8487 & 12898 \\
\hline Replicate 3 & 4199 & 8567 & 12748 \\
\hline Mean & 4181.667 & 8494 & 12798.67 \\
\hline SD & 22.42518 & 56.96198 & 70.24402 \\
\hline$\%$ RSD & 0.536274 & 0.670614 & 0.548839 \\
\hline Mean conc. found (ng/ml) & 750.09 & 1499.19 & 2249.51 \\
\hline Mean \% recovery & 98.84 & 99.19 & 100.01 \\
\hline
\end{tabular}




\section{Limit of detection (LOD)}

THIO: $10 \mathrm{ng} / \mathrm{spot}$

ACE: $250 \mathrm{ng} / \mathrm{spot}$

\section{Limit of quantification (LOQ)}

THIO: $30 \mathrm{ng} / \mathrm{spot}$

ACE: $750 \mathrm{ng} / \mathrm{spot}$

\section{Range}

THIO: $30-180 \mathrm{ng} / \mathrm{spot}$

ACE: $750-4500 \mathrm{ng} / \mathrm{spot}$

\section{Specificity}

The peak purity of both drugs was assessed by comparing the respective spectra of standard drugs and samples at peak start, peak apex and peak end positions of the spot. A blend of commonly used tablet excipients was treated as per developed procedure and the chromatogram shows no inferring peaks at retention time of the two drugs.

\section{Robustness}

By introducing small changes in the mobile phase composition, the effects on the results were examined. Mobile phases having different composition like methanol: chloroform: water (9.6: $0.2: 0.2 \mathrm{v} / \mathrm{v} / \mathrm{v}$ ) $(9.4: 0.4: 0.2 \mathrm{v} / \mathrm{v} / \mathrm{v}), \quad(9.5: 0.2: 0.3 \mathrm{v} / \mathrm{v} / \mathrm{v} / \mathrm{v})$ were tried and chromatograms were run. Time from spotting to chromatography and from chromatography to scanning was varied from $0,20,40$ and $60 \mathrm{~min}$. Robustness of the method was done at three different concentration levels 30, 60, $90 \mathrm{ng}$ per band and 750, 1500, $2250 \mathrm{ng}$ per band for THIO and ACE, respectively. Robustness of the method was determined by carrying out the analysis under conditions during which mobile phase ratio and ambient temperature were altered and the changes on the RF values were noted. The standard deviation of peak areas was calculated for each parameter and \% RSD was found to be less than $2 \%$. Results of robustness study are presented in table 3.7.

Table 3.7: Robustness study of THIO and ACE $(n=3)$

\begin{tabular}{|c|c|c|c|c|}
\hline \multirow[t]{2}{*}{ Parameter } & \multicolumn{2}{|c|}{ SD of peak area } & \multicolumn{2}{|c|}{ \% RSD } \\
\hline & THIO & ACE & THIO & ACE \\
\hline Mobile phase composition & 7.64 & 6.97 & 0.86 & 0.24 \\
\hline Amount of mobile phase & 20.87 & 8.98 & 1.08 & 0.83 \\
\hline Time from spotting to chromatography & 15.21 & 18.03 & 0.57 & 1.23 \\
\hline Time from chromatography to scanning & 6.89 & 24.11 & 0.85 & 0.77 \\
\hline Plate from different lot no. & 4.90 & 8.69 & 0.46 & 1.49 \\
\hline
\end{tabular}

\section{CONCLUSION}

HPTLC, with its advantage of low operating cost, high sample thought and minimum sample preparation need is now days preferred as routine analytical techniques for control and assurance. The validated HPTLC method employed here proved to be simple, fast, accurate, precise and sensitive, thus can be used for routine analysis of Thiocolchicoside and Aceclofenac in tablet dosage form.

\section{ACKNOWLEDGEMENT}

The authors are thankful to m/s Medley Pharmaceuticals Ltd., Baddi, India and Curex Pharmaceuticals Jalgaon, India for providing gift samples of Thiocolchicoside and Aceclofenac, respectively. The authors are thankful to Management of MAEER's Maharashtra Institute of Pharmacy, Pune and Anchrom Laboratories for providing necessary facilities to carry out the research work.

\section{CONFLICT OF INTERESTS}

\section{Declare none}

\section{REFERENCES}

1. Khopkar SM. Basic concepts of analytical chemistry. $2^{\text {nd }}$ ed. New Delhi: New age International Ltd. Publishers; 1998. p. 1, 178-9.

2. Prasanna Reddy, Battuand MS Reddy. RP-HPLC method for simultaneous estimation of paracetamol and ibuprofen in tablets. Asian J Res Chem 2009;2:70-2.

3. Frank Settle. Handbook of instrumental techniques for analytical chemistry. NJ: Prentice Hall PTR; 1997. p. 17, 19, 56, 57.

4. Sohan S Chitlange, Pradeep S Shinde, Ganesh R Pawbake, Sagar B Wankhede. Simultaneous estimation of thiocolchicoside and aceclofenac in pharmaceutical dosage form by the spectrophotometric and LC method. Pharm Lett 2010;2:86-93.

5. DA Skoog, FJ Holler, A Timothy, NW Nieman. The principle of instrumental analysis. $5^{\text {th }}$ ed. Eastern Press: Banglore; 2004. p. 1-2, 678-88, 695-6.

6. B Gowramma, S Rajan, S Muralidharan, SN Meyyanathan, B Suresh. A validated RP-HPLC method for simultaneous estimation of paracetamol and diclofenac potassium in a pharmaceutical formulation. Int J ChemTech Res 2010;2:676-80.

7. BK Sharma. Instrumental methods of chemical analysis. $21^{\text {st }} \mathrm{ed}$. Goel Publishing House, Meerut; 2002. p. 3-5, 10.

8. R Joshi, R Sharma. Development and validation of a RP-HPLC method for simultaneous estimation of three-component tablet formulation containing Acetaminophen, Chlorzoxazone, and Aceclofenac. Anal Lett 2008;41:3297-308.

9. RY Bauman. Absorption Spectroscopy, Wiley-Interscience, New York; 1975. p. 405, 569.

10. Godse VP, Deodhar MN, Bhosale AV, Sonawane RA, Sakpal PS, B orkar DD, et al. Reverse phase HPLC method for determination of aceclofenac and paracetamol in tablet dosage form. Asian J Res Chem 2009;2:387-8.

11. G Davidson. Practical pharmaceutical chemistry. $4^{\text {th }}$ ed. Vol. 2 . CBS Publishers and Distributors, New Delhi; 1997. p. 275-300.

12. Hye Suk Lee, Chang Kyun Jeong, Sung Jin Choi, Sang Beom Kim, Mi-Hyun Lee, Geon Il Ko, et al. Simultaneous determination of aceclofenac and diclofenac in human plasma by narrow bore HPLC using column-switching. I Pharm Biomed Anal 2000;23:775-81.

13. RPW Scott. Technique and practice of chromatography. Marcel dekker, New York; 1995. p. 70, 1-12.

14. NH Zawilla, M Abdul Azim Mohammad, NM El Kousy, SM ElMoghazy Aly. Determination of aceclofenac in bulk and pharmaceutical formulations. J Pharm Biomed Anal 2002;27:243-25.

15. Wagner $\mathrm{H}$, Bladt $\mathrm{S}$, Zgainski M. Plant drug analysis: a thin layer Chromatographic atlas, spring verlag, New York; 1984. p. 30.

16. KA Shaikh, AB Devkhile. Simultaneous determination of aceclofenac, paracetamol, and chlorzoxazone by RP-HPLC in pharmaceutical dosage form. J Chromatogr Sci 2008;46:649-52.

\section{How to cite this article}

- Pratima Syal, Ravinder Kumar, Govind Arora. Simultaneous estimation of thiocolchicoside and aceclofenac by HPTLC. Int J Curr Pharm Res 2017;9(4):55-60. 